\title{
PLANEJAMENTO URBANO E DIREITO DAS ÁGUAS: O PLANO DIRETOR DO MUNICÍPIO DE PASSO FUNDO-RS E A GESTÃO DOS RECURSOS HÍDRICOS ${ }^{1}$
}

\author{
Thaís Dalla Corte \\ Janaína Rigo Santin ${ }^{3}$
}

\section{RESUMO}

O município de Passo Fundo-RS destaca-se, entre outros, pelo seu potencial hídrico. Até mesmo o nome da cidade originou de um rio. As suas nascentes abastecem e são responsáveis pelo desenvolvimento de $61 \%$ dos municípios do Estado do Rio Grande do Sul. Entretanto, em decorrência da urbanização desorganizada, as suas águas estão sendo degradadas. Assim, as políticas de desenvolvimento do município buscam a sustentabilidade. Nesse contexto, intentase demonstrar a necessária relação entre planejamento urbano e gestão das águas, através da análise do Plano Diretor do município de Passo Fundo-RS, a fim de que se alcance um equilíbrio ambiental urbano. $O$ método de abordagem adotado na pesquisa será o dialético.

Palavras-Chave: Passo Fundo. Planejamento urbano. Plano diretor. Recursos hídricos. Sustentabilidade.

\section{INTRODUÇÃO}

O presente artigo tem por objetivo analisar o Plano Diretor do Município de Passo Fundo, dando enfoque às normas de uso e ocupação do solo que se relacionam com a proteção e gerenciamento dos recursos hídricos. Busca-se demonstrar a relação entre gestão urbana e gestão de águas como componente essencial para que a sustentabilidade ambiental urbana seja alcançada.

É princípio da Política Nacional de Recursos Hídricos, extraída do seu art. 30, inc. IV, a integração da gestão de recursos hídricos com a gestão ambiental. É sobre esse enfoque que o estudo será realizado, pois como destaca Kishi (2009, p. 03), "significa dizer, que as políticas públicas de saneamento básico, de uso e ocupação do solo, de resíduos perigosos, de urbanização ou ambientais devem estar integradas com as políticas públicas de recursos hídricos".

Conforme reportagem do jornal O Nacional (2009, p. 16), " $61 \%$ do Estado [do Rio Grande do Sul] depende de águas que nascem em Passo Fundo". O nome da cidade deve-se ao rio. Segundo o site da Prefeitura Municipal de Passo Fundo, o município recebeu esse nome conservando o batismo dado pelos índios: Goio-En, que significa muita água, rio fundo. Por analogia, traduz-se Passo Fundo. Os tropeiros iam até Sorocaba (São Paulo) passando por Passo Fundo, sendo o rio o seu marco referencial. Muitos deles acabaram fixando suas residências na região.

Então, "o rio virou município" (O Nacional, 2009, p.16). A cidade se desenvolveu às suas margens e, hoje, é destaque pela grande importância hídrica ao Rio Grande do Sul. Ainda segundo informações do jornal O Nacional, 'Passo 
Fundo é o berço de cinco, das 25 bacias hidrográficas do Estado. Destas mesmas terras [...] nascem as águas que abastecem e são responsáveis diretas pelo desenvolvimento de $61 \%$ dos municípios gaúchos: 302 ". Convém ressaltar que, conforme dados do IBGE (2006), o Estado é composto por 497 municípios.

Todavia, as águas do município não receberam um tratamento consciente e adequado. Ainda hoje, a maioria das suas nascentes não são preservadas e gerenciadas. Segundo informações trazidas pelo jornal O Nacional $(2009$, p. 17), somente $20 \%$ do esgoto da cidade é tratado. Apesar de todo o cuidado da legislação, faz-se necessário uma mudança comportamental da comunidade, maior atuação das autoridades e investimentos em saneamento básico.

Com uma população estimada em 168.458 habitantes em 2000, Passo Fundo surgiu a 152 anos, em 28 de janeiro de 1857, e está entre as dez cidades mais populosas do Rio Grande do Sul (é a maior cidade do norte do Estado). A maior parte da população vive na zona urbana - 163.764 habitantes - e, apenas, 4.694 habitantes na área rural. (CIOTTI et al., 2009, p. 15). Ainda, segundo esses autores, em conformidade com os dados do censo de 2000 realizado pelo IBGE,

\begin{abstract}
O abastecimento de água na área urbana do município de Passo Fundo por rede geral abrange $96,78 \%$ dos domicílios, e o abastecimento por poço ou nascente $2,50 \%$, sendo que outras formas totalizam $0,71 \%$ [...]. $\mathrm{Na}$ área rural, o abastecimento de água por rede geral atende $10,72 \%$ dos domicílios, sendo que $78,61 \%$ são atendidos por poço ou nascente e $10,65 \%$ de outras formas [...]. (2009, p.15).
\end{abstract}

É no município de Passo Fundo que se encontra a sede da Superintendência Regional do Planalto da Companhia Riograndense de Saneamento, bem como a cidade é pólo regional da bacia hidrográfica do Rio Passo Fundo. Essa abrange 30 municípios do norte do Estado, atendendo a uma área total de $4.785,7 \mathrm{~km}^{2}$ (CIOTTI et al., 2009, p. 13), com localização geográfica estratégica, sendo divisor das Grandes Bacias Hidrográficas do Uruguai e do Atlântico Sul e integrante das Bacias Hidrográficas do Alto Jacuí, Passo Fundo, Várzea, Apaue-Inhadava e Taquari-Antas, conforme art. 20 do Plano Diretor de Desenvolvimento Integrado do município de Passo Fundo-RS.

Sobre a disponibilidade de água no município destaca Ciotti et al,

\begin{abstract}
A maior parte do território gaúcho apresenta boa disponibilidade de água, mas a ocorrência de períodos de estiagem combinado ao aumento da concentração urbana e/ou a localização de algumas atividades que utilizam intensamente o recurso, já sinalizam para a escassez de água e ocorrência de racionamento em algumas regiões. (2009, p. 14).
\end{abstract}

O segundo bimestre do ano de 2009 exemplifica tal situação. Enquanto municípios do Norte e Nordeste do país sofriam com o excesso de chuvas, o Sul foi atingido por uma grave seca. Segundo informações do jornal Zero Hora trazidas pelo site G1-Brasil, 210 municípios do Estado do Rio Grande do Sul decretaram situação de emergência devido à estiagem.

Em Passo Fundo, constataram-se problemas no meio rural (em destaque no cultivo de soja, milho e produção leiteira), se encontrando, conforme dados da 
Companhia Riograndense de Saneamento (Corsan) trazidos pelo site G1-Brasil, a Barragem da Fazenda da Brigada Militar 2,9 metros abaixo do seu nível, e a barragem do Arroio Mirim 60 centímetros abaixo do normal, havendo a possibilidade de racionamento de água. Ou seja, apesar da grande disponibilidade de água do município, há períodos em que ocorre a insuficiente distribuição das precipitações pluviais, ocasionando graves períodos de seca. Logo,

\footnotetext{
Os estragos causados por secas e enchentes, como as que atingem atualmente as regiões Sul, Norte e Nordeste do país, poderiam ser evitados - ou pelo menos amenizados - com mais investimentos em políticas públicas ambientais que garantam a adaptação das cidades às mudanças climáticas. (Lourenço, 2009).
}

Nesse contexto, para que o município de Passo Fundo-RS (e, também, os demais municípios) protejam e gerenciem os seus recursos hídricos, faz-se necessário um planejamento urbano consciente das prioridades do meio ambiente. O planejamento deve garantir, recuperar, proteger e gerenciar a qualidade e quantidade das águas, recurso natural e finito, essencial à vida, ao desenvolvimento sócio-econômico e à sustentabilidade.

O plano diretor é um dos instrumentos, previsto nos artigos $4^{\circ}$ e 40 da Lei $10.257 / 01$, pelos quais os municípios realizam políticas públicas que visam 0 planejamento e a utilização dos recursos hídricos de forma integrada a ocupação ordenada e adequada do solo. A base legal dos Planos Diretores deve apresentar meios suficientes para assegurar a harmonia entre a gestão da água e dos solos, sob pena de tornar os recursos hídricos, que já são limitados, em escassos e, até mesmo, no futuro, inexistentes.

Deve-se destacar, desde já, que o Plano Diretor é um instrumento de gestão dos solos e não, especificamente, de gestão de águas. Portanto, procura-se demonstrar, a partir de tal instrumento, a relação entre gestão dos solos e gestão das águas, pois somente havendo um equilíbrio entre o meio ambiente natural e o meio ambiente construído é que o direito a cidades sustentáveis será garantido. Além do que, em decorrência do processo de urbanização precoce e desestruturado do Brasil, bem como pelo tardar na regulamentação da Política Urbana no país (os dispositivos constitucionais - arts. 182 e 183 - somente vieram a ser regulamentado em 2005, com a edição da Lei Federal 10.257/01: o Estatuto da Cidade), as cidades se desenvolveram sem planejamento, havendo construções em lugares inadequados, carência de saneamento básico, entre tantos outros, que afetam diretamente a qualidade e disponibilidade dos recursos hídricos. (ALMEIDA, 2004, p. 41).

É nesse sentido que o Plano Diretor ganha destaque na gestão das águas, pois permitir que cada município observe as suas especificidades na sua formulação e edição como, também, faz com que o cidadão possua um papel mais ativo, agindo de forma integrada com o Poder Público através da gestão. Essas características são extremamente importantes a fim de que a sustentabilidade hídrica seja alcançada, pois permite, por incidir em âmbito local, uma maior rapidez e eficiência nas tomadas de decisões, uma vez que o ser humano tende a modificar o seu comportamento de forma mais rápida quando os problemas o atingem diretamente. (CARVALHO, 2009, p. 03). 
Diante do exposto, para que os recursos hídricos sejam protegidos e utilizados de maneira sustentável é necessário que sejam geridos dentro do espaço em que se encontram, de forma integrada e não isolada ao meio ambiente e ao interesse local.

\section{PLANO DIRETOR DE DESENVOLVIMENTO INTEGRADO (PDDI) DO MUNICÍPIO DE PASSO FUNDO-RS}

Em 09 de outubro de 2006, através da Lei Complementar $n^{\circ}$. 170, surge o novo Plano Diretor do município de Passo Fundo, adequado ao Estatuto da Cidade, atendendo a determinação do art. 50 da Lei 10.257/01. O Plano Diretor, até então em vigor, era de 1984, o qual possuía vários defeitos, pouco dispondo sobre a proteção dos recursos hídricos. Explica-se a falta de tratamento atento às águas devido a sua aparência de grande disponibilidade.

Conforme 0 art. $2^{\circ}$ do novo Plano Diretor de Desenvolvimento Integrado (PDDI), sua observância é obrigatória a todos os agentes, sejam eles públicos ou privados, desde que atuem no município. Ele abrange a totalidade do território (zona urbana e rural), sendo instrumento básico da política de desenvolvimento urbano e do processo de planejamento municipal, devendo o plano plurianual, a lei de diretrizes orçamentárias e o orçamento anual incorporarem as diretrizes $e$ as prioridades nele contidas.

0 art. $3^{\circ}$, ao estabelecer os fundamentos do Plano, destaca o saneamento básico e a infra-estrutura como instrumentos de redução das desigualdades sociais, bem como enfatiza que o desenvolvimento das cidades deve ocorrer de forma sustentável, entre outras premissas. Logo, o PDDI, ao destacar o saneamento básico e a infra-estrutura como fundamentos-base da lei levou em consideração a busca de uma melhor qualidade de vida para a população, a fim de que doenças sejam evitadas e de que o meio ambiente seja preservado.

Todavia, apenas $20 \%$ do município tem o seu esgoto urbano tratado. (O Nacional, 2009, p.17). O esgoto não tratado é despejado diretamente nas reservas de água. Medidas públicas fazem-se urgentemente necessárias para que 0 artigo $3^{\circ}$ do PDDI seja efetivamente aplicado e a sustentabilidade torne-se realidade. Conforme o jornal $O$ Nacional (2009, p. 17), "no trecho situado ao lado da prefeitura municipal, por exemplo, o nível de poluição, em uma escala que vai de um a quatro, está entre os patamares três e quatro, sendo que o último é característico de esgoto".

Para que a sustentabilidade seja alcançada faz-se necessária uma gestão participativa e descentralizada dos recursos hídricos com o adequado ordenamento dos solos. De forma simples, a gestão deve ser entendida como um conjunto de ações integradas entre o poder público, usuários e da comunidade em busca do equilíbrio ambiental urbano. (BRASIL, 2001, p. 45). Nesse contexto, são medidas básicas que devem constar nos Planos Diretores: tratamento da água, limpeza pública de ruas e avenidas, coleta de resíduos orgânicos em aterros sanitários regulares, reciclagem de materiais, redes de esgotos etc. A falta de saneamento 
básico no Brasil (em destaque, no município de Passo Fundo-RS) é um dos mais graves problemas que atingem os recursos hídricos, afetando, na grande maioria dos casos, a população mais pobre. Em conseqüência, impede o desenvolvimento do país com justiça social. (REBOUÇAS, 2003, p.39).

Com relação aos princípios trazidos pelo PDDI, 0 art. $4^{\circ}$ determina que 0 município deve observar no seu desenvolvimento, além da função social da propriedade, da participação popular e da efetivação dos direitos fundamentais, uma forma harmônica de expansão com a preservação dos recursos naturais a fim de que se obtenha um crescimento qualitativo da cidade. Aqui, encontra-se presente um dos princípios fundamentais do direito das águas: a sustentabilidade hídrica.

Ou seja, deve-se conciliar o desenvolvimento "sócio-econômico-cultural e o equilíbrio hídrico" com finalidade de preservação da água doce e potável pela sua essencialidade à vida, através da sua utilização racional (leia-se de forma a evitar desperdícios), para as presentes gerações e para aquelas que estão por vir. É através da educação, conscientização, informação e da participação social que o crescimento harmônico é obtido. (COMMETTI; VENDRAMINI; GUERRA, 2008, p. 53).

Já, dispõe 0 art. $5^{\circ}$ que são objetivos do PDDI o planejamento de forma estratégica visando a sustentabilidade local e da região (inc. I), a melhoria da qualidade de vida da população (inc. VIII), entre outros. Nesse sentido, o planejamento estratégico do município leva em consideração as condições locais, visando gerenciar através de ações e análises sistemáticas o crescimento das cidades de modo que esse se realize de forma sustentável, ou seja, que não venha agredir o meio natural. (BRASIL, 2001, p. 45).

Para isso, faz-se necessário que todos os agentes participem e entendam o seu papel, criando, executando e fiscalizando as políticas públicas a fim de que o poder local se fortaleça e a cidade progrida, conforme o art. 154 do Plano Diretor. Em relação às águas o planejamento deve se centrar de modo a evitar o crescimento desordenado da demanda localizada de água, desperdícios e degradação da sua qualidade e quantidade, seja pela indústria, agricultura e usos domésticos. (BRASIL, 2001, p. 45).

Referente à qualificação ambiental, dispõem as diretrizes gerais do PDDI que o desenvolvimento municipal deve valorizar o patrimônio ambiental da cidade, em busca da sustentabilidade e da promoção dos valores históricos e culturais, visando o equilíbrio entre ambiente construído e natural, conforme 0 art. 16. Segundo a própria lei, o patrimônio ambiental abrange o histórico e cultural, assim como 0 natural e paisagístico.

Ou seja, O PDDI busca promover a qualidade ambiental urbana e o uso sustentável dos recursos naturais através do controle e do planejamento ambiental. Para tanto, deve o município desenvolver ação permanente de controle da qualidade ambiental, promover programas educacionais, garantir a preservação das áreas de permanente proteção ambiental, dos remanescentes de Mata Atlântica (Bosque Lucas Araújo), reabilitar as áreas de risco (p. ex., Beira Trilho) e gerir os vastos recursos hídricos. 
Conforme informações do projeto de manutenção permanente do Rio Passo Fundo constantes no site da Prefeitura Municipal de Passo Fundo-RS, a resolução $n^{\circ}$. 20, do Conselho Nacional do Meio Ambiente - CONAMA, ao definir as nove classes conforme o uso a que se destina a água classifica o rio Passo Fundo, o principal da cidade, com extensão de $52,5 \mathrm{~km}$ (sendo que desse total, 3,9 km de extensão se encontra no perímetro urbano - conforme dados da Prefeitura do município), como classe três, destinado ao abastecimento doméstico, irrigação de culturas e dessedentação de animais. O Jomal O Nacional (2009, p. 17), segundo afirmação de Maria Helena Bassan Benedetti - agrônoma da agência regional do Departamento de Florestas e Áreas Protegidas (Defap) - destaca que

As nascentes [das águas do município de Passo Fundo] não se encontram protegidas, principalmente pela ocupação econômica, com lavouras e criação de gado. Além disso, existe ainda a transformação de banhados com nascentes importantes em açudes. Isso altera todo o ecossistema.

Já, o art. 19 do PDDI determina as diretrizes gerais necessárias para que o município de Passo Fundo seja qualificado como ambiental. Dentro do presente estudo merecem destaque os incisos I (o qual se refere à visão ambiental integrada às políticas de desenvolvimento, visto que o município possui posição geográfica estratégica em relação às bacias hidrográficas), IV (o qual prevê a ocupação e utilização disciplinada do patrimônio ambiental), V (relacionado à disposição de que devem ser estabelecidas normas específicas de uso e ocupação do solo que visem à proteção dos recursos naturais em áreas de mananciais e recursos hídricos), entre outros. Assim, para que o município seja qualificado como ambiental deve seguir essas diretrizes a fim de que os recursos, na maioria escassos, sejam alocados da melhor maneira, promovendo as suas potencialidades e superando os conflitos que surjam referentes à poluição, degradação dos recursos naturais, saneamento, entre outros. (BRASIL, 2001, p. 45).

As disposições para a gestão do patrimônio natural e paisagístico, através do Plano do Patrimônio Natural e Paisagístico (art. 22 do PDDI), determinam que deve ser realizada "a preservação e recomposição da mata ciliar ao longo dos rios e arroios", conforme o inc. II; a recuperação e adequação das áreas degradadas e que são de preservação permanente, mormente, as nascentes e margens de rios, arroios e banhados, segundo inc. III e a educação ambiental, conforme inc. IV etc.

O maior rio do município - Rio Passo Fundo - sofre com os esgotos, poluentes, lixos e entulhos que desembocam de maneira direta ou que são carregados com a ajuda das chuvas. Tais eventos acarretam doenças, cheiro desagradável e, principalmente, enchentes, visto que os canais de drenagem do rio entopem por causa dos resíduos, conforme informações da Prefeitura.

Por esses motivos o município dispõe em seu Plano Diretor a necessidade de recuperação e proteção das nascentes e de fontes de água e possui programas para manutenção permanente do rio Passo Fundo, através de sua limpeza, bem como a conscientização da população, educação ambiental, reposição da mata ciliar, a requalificação dos recursos hídricos, entre outros. Todavia, tais medidas precisam de uma maior aplicabilidade, pois a situação dos recursos hídricos no município se encontra precária. 
Sob o capítulo "Dos Objetivos e Diretrizes Gerais da Infra-Estrutura" estabelece o PDDI a infra-estrutura como "abastecimento de água potável; a coleta, tratamento e destinação do esgoto e resíduos sólidos; o fornecimento de energia pública e domiciliar; e a drenagem urbana, dentre outros", conforme o art. 27. Ou seja, determina o Plano Diretor um saneamento ambiental integrado, com o objetivo de se obter um meio ambiente equilibrado, com níveis crescentes de salubridade, promovendo a sustentabilidade ambiental do uso e ocupação do solo o qual será realizado através da elaboração do Plano Municipal de Infra-estrutura (art. 29).

Para tal, o saneamento básico, o qual não é tido apenas pelo PDDI como simples abastecimento de água e disposição de esgotos (mas, também, coleta e tratamento de resíduos sólidos e energia elétrica), deve observar as diretrizes previstas no art. 28, a fim de que se diminua a incidência de doenças (e conseqüentes internações hospitalares, o que aumenta o custo da saúde) e 0 comprometimento dos recursos hídricos municipais.

Além do abastecimento de água em boa qualidade e quantidade, do esgotamento sanitário, da drenagem urbana de águas pluviais, da coleta e tratamento de resíduos sólidos, da limpeza urbana, iluminação pública e fornecimento de energia elétrica, o Plano Municipal obriga o município implantar e atualizar um banco de dados com informações sobre a infra-estrutura urbana e rural, bem como, em destaque, fiscalizar e controlar a captação de águas subterrâneas.

Dispõe o art. 44 que a "Macrozona de Proteção aos Mananciais ocupa as áreas rurais das bacias de captação d'água de Passo Fundo". A Macrozona estabelece "um referencial espacial para o uso e ocupação do solo na cidade, em concordância com as estratégias de política urbana". (BRASIL, 2001 p. 41). Ou seja, ela atua no desenvolvimento do município como um orientador das políticas públicas, dividindo o território em unidades as quais servem de base para a aplicação dos instrumentos constantes no Plano Diretor.

Nesse contexto, a Macrozona de Proteção dos Mananciais estabelecida nas áreas rurais (por que, como já destacado no texto, quase a totalidade dos recursos hídricos se encontram na zona rural do município) visa proteger as bacias das quais as águas são retiradas para consumo e abastecimento humano, em decorrência da crescente degradação das fontes, seja pelos produtos químicos agrícolas, poluição, desconhecimento, entre outros fatores. A própria Lei Orgânica do município ( $\mathbf{n}^{\circ}$. 1.914, de 26 de agosto de 1980) dispõe que os mananciais, cursos e reservatórios de água são zonas de segurança de saúde pública.

Já, o art. 53 se destina as Áreas de Preservação Ambiental as quais tem por objetivo proteger o meio ambiente natural e o recuperar, sendo subdivididas em Zonas de Proteção dos Recursos Hídricos, Zonas de Proteção da Mata Nativa, Zonas de Recuperação Ambiental, Zonas de Ocupação Controlada Um e Zona de Ocupação Controlada Dois. Segundo o Código Florestal (Lei $n^{\circ}$. 4.771/65) em seu art. $1^{\circ}, \S 2^{\circ}$, inc. II, as Áreas de Preservação Permanente são aquelas protegidas, cobertas ou não "por vegetação nativa, com a função ambiental de preservar os recursos hídricos, a paisagem, a estabilidade geológica, a biodiversidade, o fluxo gênico de fauna e flora, proteger o solo e assegurar o bem-estar das populações 
humanas". Daqui surgiu a subdivisão das APPs trazidas pelo Plano Diretor do Município.

Grande destaque deve se dar a essas áreas, visto que através da leitura do referido artigo se extrai que essas não podem ser objeto de exploração de nenhuma natureza, nem mesmo a partir do planejamento estratégico de exploração de forma sustentável, pois são áreas de proteção e de recuperação dos recursos naturais. A resolução $n^{\circ}$. 303 do CONAMA, de 20 de março de 2002, é quem dispõe sobre os parâmetros, definições e limites das APPs. Ainda, o Código Florestal no parágrafo único de seu art. $2^{\circ}$ dispõe que no caso de áreas urbanas dever-se-á seguir os planos diretores municipais e as leis de uso do solo, sempre observando os limites e princípios trazidos por esse artigo quanto o que deve ser objeto de preservação permanente, por exemplo, as áreas de mananciais, as matas ciliares, reservatórios d'água naturais ou artificiais, as nascentes, entre outros.

A fim de que ocorra um desenvolvimento sustentável no município e para que a qualidade de vida da população seja garantida, dispõe 0 art. 81 sobre a obrigatoriedade da construção de reservatórios nas edificações que vierem a surgir nas zonas de ocupação intensiva I e II, conforme art. 56, salvo as residências unifamiliares (art. 69), com a finalidade de retardar o escoamento das águas pluviais para a rede de drenagem. Em conjunto, deve-se instalar sistema que conduza 'toda água captada por telhados, coberturas, terraços e áreas impermeabilizadas ao reservatório", conforme $0 \$ 2^{\circ}$ do art. $81 \mathrm{ou}$, ainda, pode-se conduzir as água pluviais para outro reservatório quando o objetivo for o reúso para finalidades não potáveis, sempre observando o que dispõe as normas sanitárias vigentes e as condições técnicas específicas, a fim de evitar o consumo indevido. Ou seja, o PDDI do município exige a construção de reservatórios nas áreas com maior densidade demográfica como meio de garantir a demanda e qualidade de água em busca da sustentabilidade.

O município, através do zoneamento, estabelece "zonas homogêneas" nas quais apenas determinados usos são permitidos. (BRASIL, 2001, p. 198). Para que dentro das Zonas de Proteção de Recursos Hídricos (ZPRH) possam existir edificações essas devem obedecer aos índices urbanísticos máximos estabelecidos no Plano Diretor (art. 86). Esses índices são baixos, já que se visa proteger as encostas dos rios, nascentes e córregos, sendo área de preservação permanente e não permitindo edificações na faixa que compreende 'trinta metros ao longo do curso da água, medida em projeção horizontal, a partir da linha de contomo correspondente ao nível máximo de água do respectivo curso", conforme parágrafo único do referido artigo.

Nos casos em que não há limites físicos estabelecendo a divisa das diversas zonas municipais, para que os recursos hídricos não venham a ser prejudicados, deve se obedecer, conforme o art. 86, uma faixa de "cento e cinqüenta metros para cada lado ao longo do Rio Passo Fundo e de cem metros para os demais cursos d" água, medida em projeção horizontal, a partir da linha de contorno correspondente ao nível máximo de água do respectivo curso". Portanto, devem-se observar sempre esses limites para que os recursos hídricos não sejam prejudicados, já que a disponibilidade de água se encontra frágil diante do crescimento das cidades e seus usos múltiplos. Caso as edificações não respeitem tais dispositivos, ficam sujeitas as 
penas do art. 116 do PDDI, podendo sofrer embargos e demolição, sem direito a qualquer indenização.

O Poder Público pode interferir na utilização ou ocupação de um determinado lote ou empreendimento do proprietário se os impactos incidirem na vida da comunidade e no meio urbano. Para fazer a mediação entre os interesses privados e públicos em busca de uma maior qualidade urbana utiliza o Plano Diretor de Passo Fundo, em seu art. 121, um dos instrumentos mais importantes previstos pelo Estatuto da Cidade: o Estudo de Impacto de Vizinhança (EIV). Esse estudo viabiliza a tomada de decisões sobre "os grandes empreendimentos a serem realizados na cidade, dando voz a bairros e comunidades que estejam expostos aos impactos [...]". É através do estudo que os empreendimentos e atividades serão ou não aprovados, bem como as condições ou contrapartidas do seu funcionamento serão determinadas. (BRASIL, 2001, p. 198).

Em relação à água, pode-se extrair do art. 123 do PDDI que o Relatório de Impacto de Vizinhança (RIV) deve avaliar os aspectos da infra-estrutura urbana sobre a qualidade de vida da população (esgotos, redes de abastecimento de água etc.), aspectos ambientais (como a impermeabilização do solo, recuperação de áreas degradas, poluição, entre outros), aspectos paisagísticos (impactos sobre os recursos hídricos), aspectos econômicos (irrigação, energia elétrica, apropriação dos recursos hídricos para desenvolvimento de atividade etc.), sociais (higiene, saúde, alimentação, entre outros) e gerais (compreendem as demais análises necessárias).

Outros são os instrumentos também adotados pelo PDDI em observância a Lei 10.257/01 como parcelamento, edificação ou utilização compulsória; IPTU progressivo no tempo; desapropriação com pagamento em títulos; consórcio imobiliário; direito de preempção; outorga onerosa do direito de construir; operações urbanas consorciadas; transferência do direito de construir; direito de superfície. Dos descritos, convém destacar quanto à preservação dos recursos hídricos as operações urbanas consorciadas, pois traz novos atores para planejar o crescimento das cidades de forma sustentável, afirmando o poder local.

Conforme o art.146 do Plano, as suas disposições são "medidas coordenadas pelo Município com a participação de proprietários, moradores, usuários permanentes e investidores privados, com o objetivo de alcançar transformações urbanísticas, melhorias sociais e valorização ambiental em uma determinada área urbana". Então, fazendo um comparativo com a lei $9.433 / 97$, aqui se encontra um dos pontos mais importantes da Política Nacional de Recursos Hídricos: a gestão descentralizada e participativa entre poder público, organizações privadas e entidades sociais.

Destaca-se, portanto, a importância da participação popular na elaboração e efetivação da política urbana integrada aos recursos naturais (em destaque, os hídricos). Somente com a Constituição Federal de 1988 é que "o país consolida um processo de redemocratização política que altera o quadro referente à gestão das cidades e à política urbana nacional". (SILVA; FREIRE, 2009, p. 01). O cidadão, nesse novo modelo de gestão do interesse público, passa a ser "colaborador, cogestor, prestador e fiscalizador das atividades da Administração Pública". É nesse sentido que os municípios, em busca de uma melhor gestão democrática, criam 
conselhos, comissões, comitês a fim de que as atividades da administração sejam compatíveis com os interesses da comunidade. (BRASIL, 2001, p. 205).

Nesse sentido, dispõe o art. 152 do Plano Diretor do município de Passo Fundo que a participação e o controle social no planejamento e ordenamento territorial são assegurados através do Conselho Municipal de Desenvolvimento Integrado, das Conferências Municipais de Desenvolvimento, das consultas e audiências públicas, devendo "o órgão ou ente da administração direta e indireta responsável pelo planejamento municipal" elaborar e atualizar um sistema municipal integrado de informação (art.153).

Portanto, o Plano Diretor do município de Passo Fundo articula o uso e ocupação do solo com a gestão dos recursos hídricos, através de um planejamento participativo, em busca do desenvolvimento local socialmente justo, ambientalmente equilibrado e economicamente viável, visando garantir qualidade de vida para a população. O PPDI segue as especificações previstas no Estatuto da Cidade (Lei 10.257/2001), sendo evidente a sua preocupação com os recursos hídricos, já que o município é sede da Superintendência Regional do Planalto da Companhia Riograndense de Saneamento, é pólo regional da bacia hidrográfica do Rio Passo Fundo, se encontra sobre o Aqǘf́ero Guarani e possui grande disponibilidade de água.

\section{CONCLUSÕES}

O Plano Diretor de Desenvolvimento Integrado do município de Passo FundoRS busca, através de suas disposições, um equilíbrio adequado entre a oferta e a demanda dos recursos hídricos utilizados, a fim de que o desenvolvimento sustentável seja alcançado e desastres ecológicos sejam evitados frente 0 crescimento da cidade. A base legal apresentada pelo PDDI é suficiente para assegurar a harmonia entre a gestão da água e dos solos.

Entretanto, para que ocorra a efetivação do que dispõe o Plano, faz-se necessária a participação da sociedade na gestão, a qual não deve agir de forma incipiente e esperar pelas ações do poder público. A gestão integrada é de suma importância, pois coíbe a degradação dos recursos hídricos, evita, atenua e, até mesmo, busca recuperar os já poluídos. Essa, todavia, só é eficiente se houver conscientização da população. Conforme Freitas, o problema do uso irracional dos recursos hídricos, 'transcende a edição de regras legais. É cultural. É preciso que a população saiba a importância do uso correto da água e as conseqüências do desperdício. Afinal, o abuso é rotina de milhares de famílias”. (2008, p.21).

Analisando os dados apresentados, fica evidente a fragilidade do saneamento básico do município de Passo Fundo-RS. Apesar das múltiplas disposições do Plano Diretor e da Lei Orgânica citados na presente pesquisa, essas não são efetivamente aplicadas. Tratamento especial deve ser dado aos limites de ocupação no entorno das nascentes e ao esgoto. Maiores investimentos em políticas públicas ambientais e fiscalização fazem-se necessários a fim de que os recursos hídricos do município alcancem a sustentabilidade. 
As águas de Passo Fundo-RS devem ser gerenciadas e protegidas, pois não são importantes apenas para a subsistência do município, mas para todo o Estado do Rio Grande do Sul. Mudanças comportamentais, disseminação de educação ambiental, políticas públicas que garantam a adaptação da cidade às mudanças climáticas, programas sanitários e a participação da sociedade são os caminhos para que a ocupação do solo ocorra de forma equilibrada a gestão das águas.

O meio ambiente urbano compromete na falta de estrutura e políticas públicas os recursos naturais necessários á vida, lesando direitos dos cidadãos a saneamento, saúde, abastecimento de água, alimentação, emprego, entre outros. A utilização e o descuido com os corpos da água têm como conseqüência cidades não sustentáveis e desequilibradas ambientalmente, ferindo preceitos constitucionais e as legislações que regulamentam o assunto, como o Estatuto da Cidade, tornando os bens naturais, que já são limitados, em escassos e, até mesmo, no futuro, inexistentes.

\section{CITY PLANNIG AND LAW OF THE WATERS: THE DIRECTOR PLAN OF THE CITY OF PASSO FUNDO, RS, AND THE MANAGEMENT OF THE HYDRIC RESOURCES}

\section{ABSTRACT}

The city of Passo Fundo, RS, stands out, among others, for its water potential. Even the name of the city is derived from a river. Its springs supply and are responsible for the development of $61 \%$ of the cities in the State of Rio Grande do Sul. However, as consequence of its disordered urbanization, its waters are being degraded. Thus, the city's development policies aim for sustainability. In this context, the intent is to demonstrate the necessary relationship between urban planning and waters management, through the analysis of Passo Fundo's Director Key, in order to reach an urban environmental equilibrium. The method of approach adopted for the research will be the dialectic. Planning.

Keywords: Hydric Resources. Key Plan. Passo Fundo. Sustainability. Urban

\section{NOTAS}

1 Pesquisa vencedora do prêmio Impacto Social da XIX Mostra de Iniciação Científica da Universidade de Passo Fundo em 2009. Categoria resumo expandido.

2 Acadêmica do VI semestre do curso de Direito da Universidade de Passo Fundo e bolsista PIBIC/CNPq. No.do processo: 107169/2005-3. E-mail: tha_dallacorte@hotmail.com

3 Doutora em Direito pela UFPR, Mestre em Direito pela UFSC, Advogada, Professora da Faculdade de Direito e do Mestrado em História da Universidade de Passo Fundo-RS. E-mail: janainars@upf.br 


\section{REFERÊNCIAS}

ALMEIDA, Fernando Dias Menezes de. In: MEDAUAR, Odete; ALMEIDA, Fernando Dias Menezes de (Coord.) Estatuto da cidade: lei 10.257, de 10.07.2001, comentários. São Paulo: Revista dos Tribunais, 2004. P. 41.

BRASIL, Estatuto da cidade. Estatuto da Cidade: Lei n. 10.257, de 10 de julho de 2001, que estabelece diretrizes gerais da política urbana. - Brasília: Câmara dos Deputados, Coordenação de Publicações, 2001. P. 41-45; 198-205.

CARVALHO, Francisco Parente de. O Município e a Gestão Dos Recursos Hídricos. Disponível em:

<http://www.ecoterrabrasil.com.br/home/index.php?pg=temas\&tipo=temas\&cd=953>. Acesso em: 03 abr. 2009. P. 03.

CIOTTI, Carla Simone; BRANDLI, Elisangela Nicoloso; BRANDLI, Luciana; KALIL, Ramadan; KALIL, Rosa Maria Locatelli; BÓS, Sidiane Manfron. Gerenciamento da demanda de água: considerações preliminares para o município de Passo Fundo, $R S$. Disponível em:

<http://www.unifae.br/publicacoes/pdf/sustentabilidade/editorado.pdf>. Acesso em: 30 mar. 2009. P. 13-15.

COMMETTI, Filipe Domingos; VENDRAMINI, Sylvia Maria Machado; GUERRA, Roberta Freitas. $\mathrm{O}$ desenvolvimento do direito das águas como um ramo autônomo da ciência jurídica brasileira. In: Revista de Direito Ambiental, São Paulo, ano 13, n. 51, p. 46-64, jul.set./2008. 53 p.

FREITAS, Vladimir Passos de. Águas - Considerações Gerais. In: FREITAS, Vladimir Passos de. Águas - Aspectos Jurídicos e Ambientais. 3. ed. Curitiba: Juruá, 2008. $21 \mathrm{p}$.

G1-Brasil. Seca leva município do RS a racionamento de água. Disponível em: <http://g1.globo.com/Noticias/Brasil/0,,MUL1104220-

5598,00SECA+LEVA+MUNICIPIO+DO+RS+A+RACIONAMENTO+DE+AGUA.htm|> . Acesso em: 02 jun. 2009.

IBGE (Instituto Brasileiro de Geografia e Estatística). Divisão Territorial do Brasil e Limites Territoriais. Disponível em:

<ftp://geoftp.ibge.gov.br/Organizacao/Divisao Territorial/2008/DTB 2008.zip>.

Acesso em: 09 abr. 2009.

LOURENÇO, Luana. Investimentos ambientais podem evitar desastres com chuvas e secas, defende geógrafa. Agência Brasil. Disponível em:

$<$ http://www.agenciabrasil.gov.br/noticias/2009/05/16/materia.2009-05-

16.2570946187/view>. Acesso em: 17 abr. 2009.

KISHI, Sandra Akemi Shimada. Gestão Integrada, Participativa e Descentralizada das Águas. Disponível em: 
<http://midia.pgr.mpf.gov.br/4ccr/sitegtaguas/sitegtaguas 4/pdf/artigo1.pdf>. Acesso em: 20 jun. 2009.03 p.

O NACIONAL. 60\% do Estado depende de águas que nascem em Passo Fundo. Passo Fundo, sáb. e dom., 29 e 30 de agosto de 2009. ano 85, n. 24.187. P. 16-17.

Prefeitura Municipal de Passo Fundo-RS. Origem do nome do município. Disponível em: <http://www.pmpf.rs.gov.br/secao.php?p=237\&a=3\&pm=158>. Acesso em: 15 de abr. 2009.

Prefeitura Municipal de Passo Fundo-RS. Projeto de manutenção permanente do Rio Passo Fundo. Disponível em:

<http://uww.pmpf.rs.gov.br/secao.php?p=275\&a=2\&pm=247>. Acesso em: 15 abr. 2009.

Prefeitura Municipal de Passo Fundo-RS. Plano Diretor de Desenvolvimento Integrado (PDDI) do Município de Passo Fundo. Disponível em:

$<$ http://www.pmpf.rs.gov.br/secao.php?p=584\&a=2\&pm=77>. Acesso em: 12 abr. 2009.

REBOUÇAS, Aldo da Cunha. Proteção dos Recursos Hídricos. In: Revista de Direito Ambiental, São Paulo, ano 8, n. 32, p.33-67, out.dez./2003. 39 p.

SILVA, Catia Antonia da; FREIRE, Désirée Guichard. Participação Social, Gestão Urbana e Contribuições da Geografia: Em Busca do Humanismo

Concreto. Disponível em: <http://www.ub.es/geocrit/9porto/catiades.htm>. Acesso em: 30 mar. 2009. 01 p.

Recebido para publicação 10/12/2009

Aceito para publicação 30/12/2009 